\title{
Transcription Factor Binding Site Deletion Mutation
}

National Cancer Institute

\section{Source}

National Cancer Institute. Transcription Factor Binding Site Deletion Mutation. NCI

Thesaurus. Code C148653.

A deletion mutation where the deleted sequence includes a transcription factor binding site for a gene. 